\title{
A Conceptual Knowledge Visualisation Framework for Transfer of Knowledge: An Organisational Context
}

\author{
Hanlie Smuts $^{(\bowtie)}(\mathbb{D})$ and Iddo-Imri Scholtz \\ Department of Informatics, University of Pretoria, Pretoria, South Africa \\ hanlie.smuts@up.ac.za, iddo.imri@gmail.com
}

\begin{abstract}
Revolutionary advances in science and technology enables organisations to apply and optimise a world of visual and experiential learning in order to enhance the skills and knowledge of their employees. Furthermore, the volume and complexity of knowledge and information are such that unless a reporting structure is overlaid upon it, it may remain meaningless. Knowledge visualisation uses graphical representations to convey organisational knowledge, enabling employees to share and recall relevant knowledge. However, in order to assist organisations to create and transfer knowledge more effectively through knowledge visualisation, the aim of this study is to provide a conceptual knowledge visualisation framework for the transfer of knowledge for organisations. A conceptual knowledge visualisation framework was designed through a systematic literature review process where 15 organisational knowledge visualisation elements were identified. The 15 elements were grouped and presented in a 4-layered, embedded conceptual framework that organisations may apply to their knowledge visualisation efforts. By using such a framework, organisations may optimise learning and improve knowledge and skills of its employees.
\end{abstract}

Keywords: Knowledge visualisation framework - Knowledge transfer · Organisational knowledge $\cdot$ Knowledge sharing $\cdot$ Knowledge management

\section{Introduction}

The world is seeing revolutionary advances in science and technology, labelled the 4th Industrial Revolution or Industry 4.0 [1]. With the evolution of digital technologies, many opportunities are realised through the application of the digital technologies [2, 3]. Some of these include cyber-physical systems where control and monitoring are done by computer-based algorithms e.g. autonomous vehicles, the internet of things creating a connected world e.g. enabling smart cities, cloud computing providing ondemand availability of data storage and computing power and cognitive computing e.g. artificial intelligence $[4,5]$. The ability of organisations to apply and optimise Industry 4.0 technologies require digital citizens to have the knowledge and skills to effectively use and apply these digital technologies [6]. Both from a commercial perspective, as well as a knowledge and skill outlook, digital technologies enable two options: firstly, they provide multiple options for an organisation to embrace digital transformation and 
secondly, they enable a world of visual and experiential learning in order to enhance skills and knowledge [6, 7].

Whether an organisation addresses smart offerings for customers or digital skills for employees, the transfer and creation of knowledge may be achieved more effectively through knowledge visualisation [7]. Therefore, the aim of this research is to understand the key considerations for organisations aiming to utilise knowledge visualisation in an organisational context. Therefore, the research question that this paper aims to address is: "What are the elements of a knowledge visualisation framework in an organisational context? By addressing this question and applying such a framework, organisations are able to utilise digital technologies to visualise organisational knowledge in an attempt to optimise learning and improve knowledge and skills.

In Sect. 2 we present the background to the study followed by the research approach in Sect. 3. Section 4 details the data analysis and findings, while Sect. 5 concludes the paper.

\section{Background}

In an organisational context, blended training is defined by the proportions of face-toface versus online training material, including media-rich elements [6, 7]. The requirement is to scale blended learning and to design learning experiences that take full advantage of digital platforms and digital technologies, an attribute of industry 4.0 $[1,8]$. The transfer of knowledge is a core process in knowledge management in organisations and making knowledge visible so that it can be better accessed, discussed, valued and managed is a key objective [9, 10]. Over and above the mere conveyance of facts, knowledge visualisation aims to transfer insights, experiences, attitudes, values, expectations, perspectives, opinions and predictions [8]. Knowledge visualisation enables employees to re-construct, remember and apply insights gained through knowledge visualisation [9, 10].

In the next sections we consider knowledge visualisation as a phenomenon and organisational context of knowledge visualisation.

\subsection{Knowledge Visualisation as a Phenomenon}

Visualisation, from a scientific perspective, is an advanced field that is comprised of a resource base of accepted methods and meticulous processes which includes guidelines to assist with the development of data and information visualisations [9-11]. Knowledge visualisation on the other hand is not as mature [12,13] and therefore, lacks a generic set of guidelines [10,14]. An interconnected field and predecessor of knowledge visualisation is information visualisation and both these fields are utilising our natural abilities to successfully process visual representations. Although both these fields make use of our natural visual abilities, the way of utilising these abilities differ in both fields: Information visualisation intends to examine a large amount of abstract data to obtain new perceptions or to make the data more approachable. Knowledge visualisation, on the other hand, intends to enhance the transfer and creation of knowledge amongst people by providing a richer approach to communicate what they know. While information visualisation assists in improving the retrieval, access and 
presentation of information from large data sets, knowledge visualisation is mainly concerned with increasing knowledge-intensive communication amongst people [15].

The seminal work of Eppler and Burkhard [15] first coined the term knowledge visualisation and defined it as "the use of visual representations to improve the creation and transfer of knowledge between at least two people" [15: 3]. Based on this definition, Renaud and van Biljon [10] extended the definition as "the use of graphical means to communicate experiences, insights and potentially complex knowledge. Such means should be flexible enough to accommodate changing insights, and facilitate conversations. Such representations facilitate and expedite the creation and transfer of knowledge between people by improving and promoting knowledge processing and comprehension" [10: 3]. The aim of knowledge visualisation is to use visualisation to promote effective and efficient transfer of knowledge from one person to another [12, $13,16]$. Proper implementation of knowledge visualisation has the potential to utilise key strengths of the human cognitive processing system to improve communication and the transfer and sharing of knowledge [15, 17].

We discuss knowledge visualisation in an organisational context in more detail in the next section.

\subsection{The Organisational Context of Knowledge Visualisation}

The role of organisational learning includes the development of cross-boundary knowledge and requires new approaches to knowledge generation and transmission as employees are required to apply knowledge in- and outside of work structures $[18,19]$.

Data essentially consists of structured recordings of transactions and events and is presented without context [20]. Information is data with relevance and purpose added, while knowledge comes with insights, framed experiences, intuition, judgement and values and encompasses the scope of understanding and skills that are created by people through cognitive processes [20]. Knowledge can be categorised as either being explicit (has been articulated) or implicit (less tangible, deeply embedded knowledge) [21]. Tacit knowledge, as a dimension of implicit knowledge, is personal and contextspecific, and therefore hard to communicate and formalise [21]. In order to act on information, a person should internalise the information and achieve this by progressing through knowledge conversion processes namely socialisation, externalisation, combination and internalisation [21]. Socialisation ensures that knowledge is acquired, after which externalisation enables students to express their tacit knowledge (mental models and know-how). Combination is the process of integrating concepts, while internalisation is closely related to learning-by-doing, or experiential learning [21]. This process of knowledge application ensures that knowledge is advanced through practice, guidance, imitation and observation [19].

Knowledge visualisation in the context of organisations may therefore be described as the use of visual representations to improve the creation and transfer of knowledge, using available visual resources to create, integrate and administer knowledge [22].

In the next section we present an overview of our research approach. 


\section{Research Approach}

The overall objective of this paper was to define a knowledge visualisation framework as a tool for knowledge sharing and - recall in organisations. The purpose of such a framework is to guide organisations from two perspectives: firstly, with the visualisation of knowledge in order to improve the transfer and sharing of knowledge, and secondly, to leverage the strength of human visual processing capabilities [23].

In order to achieve the aim of this paper, a systematic literature review (SLR) was conducted [24-26]. The purpose of and contributions associated with a SLR may vary, yet the approach offers the benefit of the development of conceptual frameworks to reconcile and extend past research [27]. According to Tranfield, Denyer and Smart [28], the SLR process comprises of 3 consecutive stages: (1) planning the review, (2) conducting the review and (3) reporting and dissemination. Planning the review includes the identification of the review requirement, the preparation of the review proposal and the development of the review proposal. Conducting the review consists of the selection of studies, the study quality assessment, data extraction and data synthesis. Reporting and dissemination encompass the reporting of findings, recommendations and consideration of applicability for practice [28].

The first stage, planning, was guided by the aim of the research study, namely, to propose a knowledge visualisation framework for an organisational context. The keywords "organisation" AND "knowledge visualisation" (with accommodating the United States English "z") were used to find relevant studies in specific scientific databases, peer-reviewed publications such as journal papers, conference proceedings, books, case studies, book chapters, and technical reports identified for the SLR process. The initial search produced a list of 456 papers. The research studies were screened by applying specific criteria to exclude papers such as studies not associated with the research questions, non-English studies, and opinion-based papers. Duplicate studies retrieved were also removed. During the second stage of the SLR, conducting the review, the selected papers were analysed in detail. Knowledge visualisation elements were extracted as shown in Table 1 - summarising the knowledge visualisation framework elements, a short description of the element and the reference where the element was extracted from.

Fifteen knowledge visualisation elements were identified through the systematic review pertaining to an organisational context and where the target audience of the knowledge visualisation specifically points to employees. Two elements specifically pointed to the target audience of the knowledge visualisation namely, need and engagement. Audience need indicates key considerations relevant to the target audience such as an individual or a team, while audience engagement points to the audienceknowledge visualisation interaction with specific reference to how the knowledge visualisation enhance and facilitate learning engagement through interaction and experience. The focus of graphical excellence is on usability of the visualisation and ensuring that irrelevant items or decoration do not distract the target audience from the content of the topic. Essence refers to the identification and utilisation of the essentials, as well as their relationships, from a body of knowledge identified for visualisation, while accessibility indicates the relationship the target audience holds with the 
knowledge subject area, namely ensure that the level of abstraction is aligned to the target audience's prior knowledge of the particular knowledge subject area. The minimisation of the number of concepts in each level of knowledge visualisation points to the simplicity element, and intelligibility focuses on the objective that the knowledge visualisation should not carry ambiguity and that it is easy to understand. Uniformity of visual elements such as colour, symbols, shapes, etc. should be the same for the same kinds of information.

Table 1. Overview of the knowledge visualisation framework elements from the literature

\begin{tabular}{|c|c|c|}
\hline $\begin{array}{l}\text { Knowledge } \\
\text { visualisation element }\end{array}$ & Description & Source \\
\hline Audience need & $\begin{array}{l}\text { Consider for whom the visualisation is intended e.g. an } \\
\text { individual, a class, a group, a community, etc. and } \\
\text { ensure that the intended audience need is met }\end{array}$ & $\begin{array}{l}{[16,29,} \\
30]\end{array}$ \\
\hline $\begin{array}{l}\text { Audience } \\
\text { engagement }\end{array}$ & $\begin{array}{l}\text { Enhance and facilitate learning engagement through } \\
\text { interaction and experience }\end{array}$ & {$[16,22]$} \\
\hline Graphical excellence & $\begin{array}{l}\text { Focus on usability of the visualisation and avoid } \\
\text { irrelevant elements that may distract the audience from } \\
\text { the content of the topic }\end{array}$ & $\begin{array}{l}{[22,31,} \\
32]\end{array}$ \\
\hline Essence & $\begin{array}{l}\text { Identify and utilise the essentials and their relationships } \\
\text { from a body of knowledge }\end{array}$ & $\begin{array}{l}{[16,33,} \\
34]\end{array}$ \\
\hline Accessibility & $\begin{array}{l}\text { Ensure that the level of abstraction is aligned to the } \\
\text { audience's prior knowledge of the knowledge subject } \\
\text { area }\end{array}$ & {$[31,35]$} \\
\hline Simplicity & $\begin{array}{l}\text { Minimize the number of concepts in each level of } \\
\text { visualisation }\end{array}$ & {$[36,37]$} \\
\hline Intelligibility & $\begin{array}{l}\text { Ensure that the visualisation does not carry ambiguity } \\
\text { and is easy to understand }\end{array}$ & {$[29,38]$} \\
\hline Uniformity & $\begin{array}{l}\text { Use of visual elements such as colour, symbols, shapes, } \\
\text { etc. should be the same for the same kinds of } \\
\text { information }\end{array}$ & {$[34,39]$} \\
\hline Context & $\begin{array}{l}\text { Present the overview and detail. Overview gives } \\
\text { context information of a field, while detail gives more } \\
\text { information about a part of the overview. The } \\
\text { boundaries around elements and the connections to } \\
\text { other elements should be clear }\end{array}$ & $\begin{array}{l}{[16,30,} \\
32,40]\end{array}$ \\
\hline Cohesion & $\begin{array}{l}\text { Clearly show the relationship between knowledge } \\
\text { concepts and how it works together }\end{array}$ & $\begin{array}{l}{[18,35,} \\
38,40]\end{array}$ \\
\hline Explanatory power & $\begin{array}{l}\text { Visualisation must have explanatory power and not } \\
\text { merely descriptive value. The knowledge visualisation } \\
\text { requirement must be considered in this instance i.e. is it } \\
\text { for recall, sharing new insights or elaborating existing } \\
\text { knowledge }\end{array}$ & $\begin{array}{l}{[16,20,} \\
32]\end{array}$ \\
\hline
\end{tabular}


Table 1. (continued)

\begin{tabular}{l|l|l}
\hline $\begin{array}{l}\text { Knowledge } \\
\text { visualisation element }\end{array}$ & Description & Source \\
\hline $\begin{array}{l}\text { Familiarity } \\
\text { association }\end{array}$ & $\begin{array}{l}\text { Utilisation of recognisable and familiar visual images } \\
\text { associated with real-world experiences, ensure that } \\
\text { visualisation elements are recognised rather than } \\
\text { recalled }\end{array}$ & {$[22,39]$} \\
\hline Legend & $\begin{array}{l}\text { Provides the information required for clarifying and } \\
\text { explaining the knowledge visualisation meaning and } \\
\text { interpretation }\end{array}$ & $\begin{array}{l}{[36,41-} \\
43]\end{array}$ \\
\hline Knowledge transfer & $\begin{array}{l}\text { Process of transferring knowledge from one part of the } \\
\text { organisation to another by organising, creating, } \\
\text { capturing or distributing knowledge and ensuring its } \\
\text { availability for future users }\end{array}$ & {$[16,18$,} \\
\hline Visual integrity & $\begin{array}{l}\text { The knowledge visualisation should not distort the } \\
\text { underlying knowledge or create a false impression or } \\
\text { interpretation of that knowledge }\end{array}$ & {$[30-32$,} \\
\hline
\end{tabular}

Context is about presenting both the detail required for the knowledge visualisation, as well as the overview of where the detailed portion fits in. Context in an organisation highlights the combination of internal and external factors relevant to the organisation that may impact its products, services, business models, operating model, etc. Cohesion is the principle of working together and in the context of knowledge visualisation, it implies that the relationship among knowledge concepts, must be shown clearly. The explanatory power element ensures that knowledge visualisation has both explanatory and descriptive value. Descriptive value gives details and describes the knowledge that the target audience needs to understand, while explanatory value gives the reasons for it. In the organisational context, its application is closely related to whether knowledge recall is required, whether new insights are shared or whether existing knowledge is elaborated upon. By associating knowledge visualisation with familiar real world images, the target audience is enabled to recognise and interpret visuals rather than to have to remember and recall meaning. The legend element provides the information needed for the knowledge visualisation to make sense and assists in explaining meaning and interpretation. The process of transferring knowledge from one part of the organisation to another by organising, creating, capturing or distributing knowledge and ensuring it is available for future users, depicts the knowledge transfer cognitive process elements. The last element, visual integrity, points to the principle that the knowledge visualisation should have uncompromising adherence to underlying knowledge and should not create a false impression or interpretation of that knowledge.

The purpose of the 15 knowledge visualisation elements that were extracted is to guide organisations on how to approach their knowledge visualisations in order to improve the transfer and sharing of knowledge in the organisation. In the next section we discuss the conceptual framework for knowledge visualisation in an organisation, in more detail. 


\section{Conceptual Knowledge Visualisation Frameworks for Organisations}

The aim of this paper is to define a knowledge visualisation framework as a tool for organisations in support of improved knowledge transfer, -sharing and -management. In terms of the final stage of the SLR, reporting and dissemination, the list of 15 elements identified, were considered, as well as its contribution at different levels in an organisational context.

According to Jabareen [45: 58], "conceptual frameworks aim to help us understand phenomena rather than to predict them". By applying the conceptual framework analysis [45] and considering the unique features and constructs of the elements defined in Table 1, we identified 4 impact levels in the organisation as depicted in Table 2: target audience, design elements, design principles and organisational purpose.

Table 2. Organisational impact of 15 knowledge visualisation elements identified

\begin{tabular}{l|l|l|l}
\hline $\begin{array}{l}\text { Knowledge } \\
\text { visualisation element }\end{array}$ & $\begin{array}{l}\text { Organisational } \\
\text { impact level }\end{array}$ & $\begin{array}{l}\text { Knowledge visualisation } \\
\text { element }\end{array}$ & $\begin{array}{l}\text { Organisational } \\
\text { impact level }\end{array}$ \\
\hline Audience need & Target audience & Context & Target audience \\
\hline $\begin{array}{l}\text { Audience } \\
\text { engagement }\end{array}$ & Target audience & Cohesion & Design principle \\
\hline Graphical excellence & Design element & Explanatory power & Design principle \\
\hline Essence & $\begin{array}{l}\text { Organisational } \\
\text { purpose }\end{array}$ & Familiarity association & Design principle \\
\hline Accessibility & Target audience & Legend & Design element \\
\hline Simplicity & Design principle & $\begin{array}{l}\text { Knowledge transfer } \\
\text { cognitive process }\end{array}$ & $\begin{array}{l}\text { Organisational } \\
\text { purpose }\end{array}$ \\
\hline Intelligibility & Design principle & Visual integrity & Design element \\
\hline Uniformity & Design principle & & \\
\hline
\end{tabular}

The main driver of knowledge visualisation is the organisational purpose i.e. the reason why the knowledge visualisation is done or created. Purpose talks to the required scope within the organisational body of knowledge that must be visualised with the aim to achieve transferring and sharing knowledge, as well as communicating ideas and insights. Design principles depicts the key considerations when designing the knowledge visualisation aligned to the purpose, and aims to establish a good design that is simple to understand, cohesive and explanatory in nature. Employees must be able to easily associate the knowledge visualisation with the organisational purpose and the objective of what needs to be achieved with the knowledge transfer. Design elements is another impact level and includes graphical excellence, legend and visual integrity. These are typical elements that relates to the interface with employees and in particular the usability of the knowledge visualisation interface.

The target audience impact level includes knowledge visualisation elements related to the target audience in the organisation, namely the employees. Elements impacting 
the employees in the organisation includes the need of different employees e.g. individuals, functional teams, project teams, etc. Knowledge visualisation must address the need from the particular employee or employee group it is intended for. Related to audience need, is audience engagement as the interaction with the visualised knowledge should enhance and facilitate learning engagement or the employee or employee group. Context and accessibility are also elements that impact the employees engaging with the knowledge visualisation as organisational boundaries and the particular scenario that must be visualised, is a key consideration. Accessibility is a key enabler as this element needs to ensure that an employee can place the knowledge visualisation subject area in context and interpret it within the organisational context.

However, the 4 impact levels of the 15 knowledge visualisation elements identified is not standalone and are interrelated. By bearing Table 2 in mind and considering the interrelated nature of the impact levels, an embedded and layered knowledge visualisation framework for organisations may be defined and is depicted in Fig. 1. Figure 1 illustrates 4 layers with organisational purpose as the inner most layer, followed by design principles, design elements and ultimately target audience. For each layer, the particular elements relevant to that layer are shown. Organisational purpose at the core, impacts greatly on the focus of the knowledge visualisation and each layer contribute further to guide or clarify what is required for the organisation.

An example of such knowledge visualisation application relates to software requirements elicitation in an organisation. The required elicitation process in an organisation is acknowledged as one of the most crucial, knowledge-intensive processes and is built on the knowledge of the stakeholders. During requirement elicitation, each stakeholder communicates their requirements in a distinctive way which could lead to ambiguous and vague understandings translated into the capturing of inaccurate requirements. The involved stakeholders have a diverse knowledge background that requires collaboration in order to reach an agreement on the elicited requirements for an Information Systems development project.

In order to deal with the potential requirements elicitation challenges encountered, attention needs to be given to the identification and assessment of knowledge involving the identification and assessment of required knowledge benefits. By utilising the proposed framework for knowledge visualisation in an organisational context (Fig. 1) as a guide, insights, experiences, point of views, values, assumptions, outlook, beliefs and prognosis may be transferred in such a manner that empowers an employee to rebuild, recall and implement these insights accurately. Therefore, knowledge visualisation could serve as a viable option to address the challenges encountered in requirements elicitation.

By applying the conceptual framework presented in Fig. 1, organisations are guided towards relevant and fit-for-purpose knowledge visualisations, aligned to real world scenarios and adding value within the context of the particular organisation. 


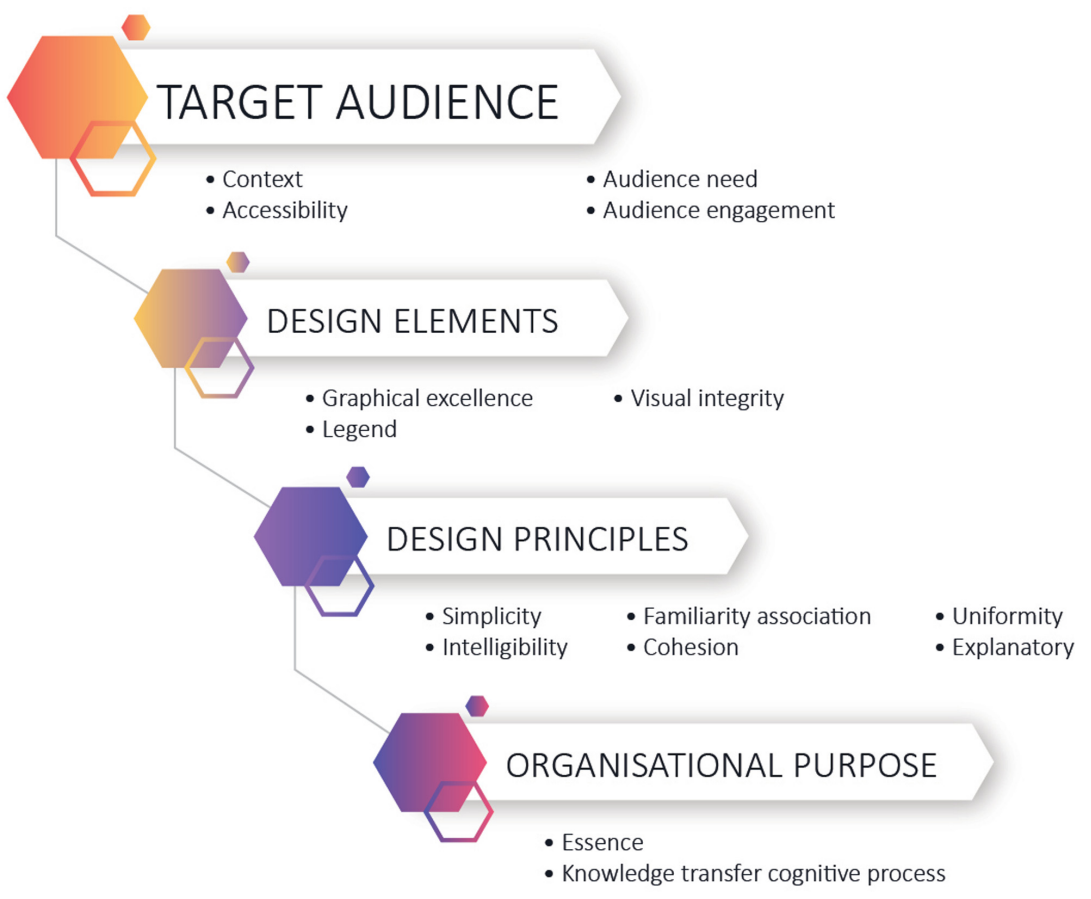

Fig. 1. Framework for knowledge visualisation in an organisational context

\section{Conclusion}

Organisations have the opportunity to leverage digital technologies for the visualisation of organisational knowledge with the aim to empower employees with knowledge sharing and -recall. In addition, the volume and complexity of knowledge and information amplified by big data management and data-driven decision-making requirements, requires structure to ensure that it is meaningful. The emerging field of knowledge visualisation uses graphical representations to convey complex insights, experiences, methods, etc. enabling the employee engaging with the knowledge visualisation to reconstruct and remember the relevant knowledge. In order to assist organisations in creating fit for purpose knowledge visualisations, the aim of this study was to extract, design and propose a conceptual knowledge visualisation framework.

The proposed knowledge visualisation framework was derived through a SLR process by extracting 15 relevant elements for knowledge visualisation in an organisational context and by considering the organisational impact level of each element identified. The four, layered and embedded impact levels form the basis for the conceptual knowledge visualisation framework that organisations may reference when utilising knowledge visualisation.

In terms of future research opportunity, the conceptual knowledge visualisation framework presented in this study may be tested in a real-world scenario in an 
organisation and the application of the framework measured. Through such application, additional, relevant knowledge visualisation elements may be identified and the proposed framework enriched.

\section{References}

1. Tabarés, R.: Harnessing the power of Digital Social Platforms to shake up makers and manufacturing entrepreneurs towards a European Open Manufacturing ecosystem. Res. Innov. Action (2016)

2. Ganju, K.K., Pavlou, P.A., Banker, R.D.: Does information and communication technology lead to the wellbeing of nations? A country-level empirical investigation. MIS Q. 40(2), 417-430 (2016)

3. Rocha, L., et al.: Cloud management tools for sustainable SMEs. Procedia CIRP 40, 220 224 (2016)

4. Pfohl, H., Yahsi, B., Kurnaz, T.: The impact of Industry 4.0 on supply chain. In: Kersten, W., Blecker, T., Ringle, C. (eds.) Innovations and Strategies for Logistics and Supply Chains, pp. 31-58 (2015)

5. Martinez, F.: Process excellence the key for digitalisation. Bus. Process Manag. J. 25(7), 1716-1733 (2019)

6. Khairuddin, S.M., Omar, F.I., Ahmad, N.: Digital inclusion domain in entrepreneurship: a preliminary analysis. Adv. Sci. Lett. 2018(24), 2721-2724 (2018)

7. O'Connor, B.: Digital Transformation A Framework for ICT Literacy, in A Report of the International ICT Literacy Panel (2007)

8. Prifti, L.: Professional Qualification in "Industrie 4.0": Building a Competency Model and Competency-Based Curriculum. Faculty Informatics, p. 258. Technischen Universität München (2019)

9. Kelleher, C., Wagener, T.: Short communication: ten guidelines for effective data visualization in scientific publications. Environ. Model Softw. 26(6), 822-827 (2011)

10. Renaud, K., van Biljon, J.: Charting the path towards effective knowledge visualisations. In: Proceedings of the South African Institute of Computer Scientists and Information Technologists SAICSIT 2017. ACM Press, Thaba 'Nchu (2017)

11. Elmqvist, N., Fekete, J.D.: Hierarchical aggregation for information visualization: overview, techniques, and design guidelines. IEEE Trans. Vis. Comput. Graph. 16(3), 439-454 (2010)

12. Cañas, A.J., et al.: Concept maps: integrating knowledge and information visualization. In: Tergan, S.-O., Keller, T. (eds.) Knowledge and Information Visualization. LNCS, vol. 3426, pp. 205-219. Springer, Heidelberg (2005). https://doi.org/10.1007/11510154_11

13. Eppler, M.J.: What is an effective knowledge visualization? Insights from a review of seminal concepts. In: 15th International Conference on Information Visualisation (2011). https://doi.org/10.1109/iv.2011.13

14. Meyer, R.: Knowledge Visualization in Trends in Information Visualization, pp. 23-30. University of Munich, Munich (2010)

15. Eppler, M.J., Burkhard, R.: Knowledge visualization: towards a new discipline and its fields of application. Lugano, Università della Svizzera italiana, Faculty of Communication Sciences, Institute for Corporate Communication (2004)

16. Burkhard, R.A.: Towards a framework and a model for knowledge visualization: synergies between information and knowledge visualization. In: Tergan, S.-O., Keller, T. (eds.) Knowledge and Information Visualization. LNCS, vol. 3426, pp. 238-255. Springer, Heidelberg (2005). https://doi.org/10.1007/11510154_13 
17. Keller, T., Tergan, S.-O.: Visualizing knowledge and information: an introduction. In: Tergan, S.-O., Keller, T. (eds.) Knowledge and Information Visualization. LNCS, vol. 3426, pp. 1-23. Springer, Heidelberg (2005). https://doi.org/10.1007/11510154_1

18. Štorga, M., Mostashari, A., Stankovic, T.: Visualisation of the organisation knowledge structure evolution. J. Knowl. Manag. 17(5), 724-740 (2014)

19. Smuts, H., Hattingh, M.J.: Towards a knowledge conversion model enabling programme design in higher education for shaping industry-ready graduates. In: Kabanda, S., Suleman, H., Gruner, S. (eds.) SACLA 2018. CCIS, vol. 963, pp. 124-139. Springer, Cham (2019). https://doi.org/10.1007/978-3-030-05813-5_9

20. Boehnert, J.: Knowledge visualization in environmental communication, in relating systems thinking and design (RSD5). In: Jones, P. (ed.) 2016 Symposium, Ontario College of Art and Design, Ontario, Canada (2016)

21. Nonaka, I., Toyama, R., Konno, N.: SECI, Ba and leadership: a unified model of dynamic knowledge creation. Long Range Plann. 33, 5-34 (2000)

22. Eppler, M., Burkhard, R.: Visual representations in knowledge management: framework and cases. J. Knowl. Manag. 11(4), 112-122 (2007)

23. Renaud, K., van Biljon, J.: A framework to maximise the communicative power of knowledge visualisations. In: Conference of the South African Institute of Computer Scientists and Information Technologists 2019 (SAICSIT 2019). ACM, New York (2019)

24. Rouhani, B.D., et al.: A systematic literature review on enterprise architecture implementation methodologies. Inf. Softw. Technol. 62, 1-20 (2015)

25. Aromataris, E., Pearson, A.: The systematic review: an overview. AJN Am. J. Nurs. 114, 53-58 (2014)

26. Hart, C.: Doing a Literature Review: Releasing the Social Science Research Imagination. SAGE Publications, London (2018)

27. Palmatier, R.W., Houston, M.B., Hulland, J.: Review articles: purpose, process, and structure. J. Acad. Market. Sci. 46(1), 1-5 (2018)

28. Tranfield, D., Denyer, D., Smart, P.: Towards a methodology for developing evidenceinformed management knowledge by means of systematic review. Br. J. Manag. 14, 207222 (2003)

29. Lanfranchi, V., et al.: A semantic knowledge management framework for informal communication exchanges. In: 10th International Semantic Web Conference (ISWC 2011), Bonn, Germany (2011)

30. Marchese, F.T., Bannisi, E.: Knowledge Visualization Currents: From Text to Art to Culture. Springer, New York (2013). https://doi.org/10.1007/978-1-4471-4303-1

31. Mazumdar, S., Varga, A., Lanfranchi, V., Petrelli, D., Ciravegna, F.: A knowledge dashboard for manufacturing industries. In: García-Castro, R., Fensel, D., Antoniou, G. (eds.) ESWC 2011. LNCS, vol. 7117, pp. 112-124. Springer, Heidelberg (2012). https://doi. org/10.1007/978-3-642-25953-1_10

32. Figueiras, A.: How to tell stories using visualization: strategies towards Narrative Visualization. Faculdade de Ciências Sociais e Humanas and the Universidade NOVA de Lisboa: Lisbon (2014)

33. Joel-Edgar, S., Gopsill, J.: Understanding user requirements in context: a case study of developing a visualisation tool to map skills in an engineering organisation. In: International Conference on Information Management and Processing (ICIMP). IEEE, London (2018)

34. Fadiran, O., Van Biljon, J., Schoeman, M.: How can visualisation principles be used to support knowledge transfer in teaching and learning? In: Proceedings of the 2018 Conference on Information Communications Technology and Society (ICTAS 2018). IEEE, Durban (2018) 
35. Seppänen, H., Virrantaus, K.: Shared situational awareness and information quality in disaster management. Saf. Sci. 77, 112-122 (2015)

36. Jiawei, H., Bailey, A., Sutcliffe, A.: Visualisation design knowledge reuse. In: Eighth International Conference on Information Visualisation. IEEE, London (2004)

37. Yaacob, S., et al.: Giving the boss the big picture: demonstrating convergence visualization design principles using business intelligence and analytical tools. J. Fundam. Appl. Sci. 10 (5S), 1328-1337 (2018)

38. Olshannikova, E., et al.: Visualizing Big Data with augmented and virtual reality: challenges and research agenda. J. Big Data 2(1), 1-27 (2015)

39. Grainger, S., Mao, F., Buytaert, W.: Environmental data visualisation for nonscientific contexts: literature review and design framework. Environ. Model Softw. 85, 299-318 (2016)

40. Succar, B., et al.: A proposed framework to investigate building information modelling through knowledge elicitation and visual models. In: Conference of the Australasian Universities Building Education Association, Melbourne (2007)

41. Heer, J., Shneiderman, B., Park, C.: A taxonomy of tools that support the fluent and flexible use of visualizations. Interact. Dyn. Vis. Anal. 10, 1-26 (2012)

42. Candello, H., Fernandes Cavalcante, V., Braz, A., De Paula, R.A.: A validation study of a visual analytics tool with end users. In: Marcus, A. (ed.) DUXU 2014. LNCS, vol. 8520, pp. 381-391. Springer, Cham (2014). https://doi.org/10.1007/978-3-319-07638-6_37

43. Shamim, A., Balakrishnan, V., Tahir, M.: Evaluation of opinion visualization techniques. Inf. Vis. 14(4), 339-358 (2015)

44. Vande Wiele, P., Ribiere, V.: Using knowledge visualisation techniques to support the development of curriculum for employability: exploring the capability tree representation. Int. J. Knowl. Learn. 9(1/2), 43-62 (2014)

45. Jabareen, Y.: Building a conceptual framework: philosophy, definitions, and procedure. Int. J. Qual. Methods 8(4), 49-62 (2009) 